\title{
Role of blood glucose and fat profile in lung function pattern of Indian type 2 diabetic subjects
}

\author{
Morteza A. Khafaie ${ }^{1,2^{*}}$ D, Sundeep S. Salvi ${ }^{3}$, Chittaranjan S. Yajnik ${ }^{4}$, Fakher Rahim ${ }^{5}$ and Behzad Khafaei ${ }^{6}$
}

\begin{abstract}
Background and objectives: It has been hypothesized that changes in lung function can occur in patients with diabetes. Nevertheless, it is unclear how much of this correlation links with biomarkers of metabolism disorder. We have investigated the association between hypoglycaemic and fat profile with lung function in Indian diabetic subjects.
\end{abstract}

Design: Prospective observational study.

Setting: Diabetes care unit of King Edward Memorial (KEM) hospital.

Patients: Out of 465 patients who agreed to participate in this study, valid lung function data were available from 347 Type 2 diabetic subjects.

Measurements: Pulmonary function test including predicted forced vital capacity (\% FVC), predicted forced expiratory volume in 1 second (\% FEV F $_{1}$ and $\mathrm{FEV}_{1} / \mathrm{FVC}$ ratio were assessed. We also examined fat profile, glucose, HbA1c, hemoglobin and other hematological parameters.

Results: Four hundred sixty-five subjects aged $55 \pm 11$ participated in the study. Predicted forced vital capacity, \% FEV and $\mathrm{FEV}_{1} / \mathrm{FVC}$ ratio was $85.88 \pm 13.53,85.87 \pm 14.06$ and $82.03 \pm 6.83$, respectively. Also, approximately 8 to $17 \%$ of the participant reported having at least one chronic respiratory symptom or lung disease. We found that high glycaemic measures (i.e. fasting and post-meal plasma glucose) are linked with dyspnea. In addition, HDL (high-density lipoprotein) concentration was directly associated with \% FVC.

Conclusions: It is difficult to draw a clear conclusion about the cause-effect relationship or clinical impact based on this study alone. However, identification of clinically meaningful elements for developing a screening program is critical.

Keywords: Respiratory distress syndrome, Diabetes mellitus, Hyperglycaemia, Fat profile; risk factors

\section{Background}

Diabetes mellitus (DM) describes a metabolic disorder of multiple etiologies characterized by chronic hyperglycaemia with disturbances of fat, protein and carbohydrate metabolism due to impairment in insulin secretion, insulin action, or both [1]. In this

* Correspondence: khafaie-m@ajums.ac.ir

${ }^{1}$ Social Determinants of Health Research Center, Ahvaz Jundishapur University of Medical Sciences, Ahvaz, Iran

${ }^{2}$ Department of Public Health, Faculty of Health, Ahvaz Jundishapur

University of Medical Sciences, Ahvaz, Iran

Full list of author information is available at the end of the article condition, the body needs to increase its medication and eventually insulin infusion is necessary [2]. In many developing regions such as India, thus, lack of appropriate medical care especially due to health gradient leads these populations to develop diabetes at lower ages and BMI [3]. Earlier onset of diabetes may result in the development of severe complications [4].

The lung is one of the target organs in diabetes of which the damage is quite subclinical and often ignored by patients and physicians [5]. Respiratory distress is a public life-threatening condition with an estimated 150,000 cases in the United States annually. Some evidence, but not all, proposed DM as a risk modifier for 
respiratory distress, especially acute respiratory distress syndrome (ARDS). Some studies have reported DM to be associated with lower development of respiratory distress [6-8], whereas others found that DM increases the risk of this disorder [9].

A high proportion of patients with chronic respiratory disease have simultaneous metabolic disorders [10-12]. Although some evidence has been suggested, chronic respiratory disorders (i.e. lung volume, pulmonary diffusing capacity, control of ventilation, bronchomotor tone, and neuroadrenergic bronchial innervation) are a risk factor for diabetes [13, 14], others reported diabetes as a risk factor for respiratory disorders [15]. Furthermore, metabolic disorders, especially diabetes that generally manifested with obesity, are associated with a substantial loss of pulmonary function in a restrictive pattern [16-19].

Many hypotheses have emerged to elucidate the pathogenesis of the diabetic lung injury, and characteristic "diabetic lung" [5]. Oxidative stress, non-enzymatic glycation of proteins, and the polyol pathway have been recognized to be elaborated in the etiology of diabetic lung injury [20]. We speculate that glycaemic control and fat profile that linked with collagen and elastin changes [21] can lead to significant structural changes in the respiratory system.

\section{Patients and methods}

\section{Study design and participation}

Type 2 diabetic subjects attended diabetes care unit of King Edward Memorial (KEM) hospital, between March and December 2011, and consented to participate in the study $(N=465)$, and were administered a standard questionnaire (available online as supplementary material [22]). The questionnaire was designed to capture demographic data, medical history of the patient and data related to the duration of activity, the source of indoor air pollution, chronic respiratory symptoms (CRS), asthma and COPD. CRS included: chronic cough (cough or phlegm apart from common cold that has been accruing for at least 3 months of the year for the last 2 years), dyspnea (any attack of shortness of breath with wheeze, apart from common colds in the last 12 months), wheezing (a wheeze for at least 6 months of the year, apart from common colds), chest tightness (feeling of tightness in the last 12 months in their chest), and allergy (symptoms such as hay fever or any other condition making the nose runny or stuffy, apart from common colds, associated with redness of eyes, itching, burning, and eczema present in most days of the week).

Blood samples also were drawn to measure various biochemical parameters, including fat profile, glucose, HbA1c, hemoglobin and other hematological parameters. Complete details of the survey design and examination procedures have been published elsewhere [23]. Subjects with history of recent eye surgery, recent abdominal surgery, stroke that is affecting the face, recent myocardial infarction, smoking cigarettes, using short-acting bronchodilator such salbutamol (last 4-6h) or long-acting agents, having a heavy meal, having flu-like illness or cold could affect the spirometry results were excluded from the study.

\section{Procedure}

Subjects were asked to remove tight clothing such as ties and belts and perform the spirometry test three times (acceptable and repeatable [22]), using ultrasonic spirometer (ndd, Switzerland), and the best ones of the three results were taken into consideration. The examinations were performed with the subject in a sitting position wearing a nose clip and using a disposable mouthpiece. The quality of spirometry measurements was controlled by chest research foundation (CRF) specialists. Referees reviewed all loop recordings and excluded those without at least three satisfactory tests (see details in [24]. We interpreted the subject's lung function as $90 \%$ of the European Community for Steel and Coal (ECSC) value as a reference [25].

\section{Statistical analyses}

For all models, the dependent variables were percent predicted FVC (\%FVC), percent predicted $\mathrm{FEV}_{1}\left(\% \mathrm{FEV}_{1}\right)$, cough, dyspnea, allergy, history of asthma or COPD. Also, each biomarker (i.e. FPG, $2_{\text {hrs }}$ PG, Hemoglobin, HbA1c, total cholesterol, LDL cholesterol, HDL cholesterol, triglyceride, and WBC), a series of regression models were performed independently. Initial models assessed the linear association of the biomarkers with PFT (i.e. \%FVC and $\% \mathrm{FEV}_{1}$ ) adjusting for potential confounding factors including age, gender, BMI, cigarette smoking and medication (i.e. aspirin, statin, and TZD) as appropriate. Results are presented as \% change in mean \% predicted PFT for $1 \mathrm{SD} \mu \mathrm{g} / \mathrm{m}^{3}$ increments in biomarkers using the following formula: \%change $=($ Coef. $/$ mean $) 1$ SD*100, where, Coef. $=$ coefficients of association, Mean $=$ average $\%$ predicted the value of $\mathrm{FEV}_{1}$ and $\mathrm{FVC}, 1 \mathrm{SD}=1$ Standard Deviation of biomarkers. Further, we studied the odds ratio of having a chronic cough, dyspnea, asthma and COPD for 1 SD increase in biomarkers, using logistic regression. Exponential of estimated coefficients (equal to odd ratio) was reported. The significance threshold of $p=$ 0.05 was used in all analyses. All statistical analyses were performed using STATA version 11.1 software (STATA Corporation, College Station, TX).

\section{Results}

Descriptive characteristics of the study population are depicted in Table 1 . Out of 465 patients who agreed to participate, valid lung function data were available from 
Table 1 Descriptive characteristics of study population

\begin{tabular}{|c|c|c|}
\hline Characteristics & $N$ & Diabetic subjects \\
\hline Male & 465 & $268(58)$ \\
\hline Age, yrs.* & 465 & $54.58(11.11)$ \\
\hline $\mathrm{BMI}, \mathrm{kg} / \mathrm{m}^{2 *}$ & 462 & $26.71(4.08)$ \\
\hline Waist-Hip ratio* & 314 & $0.96(0.10)$ \\
\hline FVC, Liters* & 374 & $2.49(0.52)$ \\
\hline $\mathrm{FEV}_{1}$, Liters* & 374 & $2.02(0.44)$ \\
\hline$\% \mathrm{FEV}_{1} / \mathrm{FVC}^{*}$ & 374 & $82.03(6.83)$ \\
\hline$\%$ predicted FVC & 374 & $85.88(13.53)$ \\
\hline$\%$ predicted FEV & 374 & $85.87(14.06)$ \\
\hline Smoking & 465 & $34(7.31)$ \\
\hline Tobacco & 465 & $97(21.00)$ \\
\hline Alcohol & 462 & $76(16.45)$ \\
\hline Non-vegetarian* & 465 & $295(63.00)$ \\
\hline Chronic cough* & 465 & $51(11.00)$ \\
\hline Dyspnea $_{(\mathrm{MRC} 1-5)^{*}}$ & 465 & $145(31.00)$ \\
\hline Wheezing* & 465 & $40(8.60)$ \\
\hline Tightness* & 465 & $39(8.40)$ \\
\hline Allergy symptom & 465 & $81(17.40)$ \\
\hline COPD history & 465 & \\
\hline self* & & $10(2.40)$ \\
\hline family & & $6(1.50)$ \\
\hline Asthma history & 465 & \\
\hline self* & & $17(4.20)$ \\
\hline family * & & $66(16.20)$ \\
\hline TZD & 465 & $38(11.50)$ \\
\hline Aspirin & 465 & $162(48.00)$ \\
\hline Statin & 465 & $190(56.5)$ \\
\hline
\end{tabular}

Data is shown as $\mathrm{n}(\%)$ and mean (SD); The difference between groups was tested by t-test and Chi-square, as appropriate; The test was adjusted for age, gender, and BMI as appropriate

*indicate $p<0.05$
347 diabetic subjects. There were no significant differences between 347 patients for whom lung function was available and the rest of subjects in terms of age, gender, and BMI. More than half of diabetic subjects patients were on at least one of an anti-inflammatory agent such as aspirin, statins, and TZD (Thiazolidinedione).

\section{Blood biomarkers}

Data obtained from patients recorded profiles up to 1 month before enrollment for the lung function test. All variables were normally distributed except triglyceride and WBC. Therefore, these variables were logarithmically transformed (Table 2).

Women had lower $\mathrm{Hb}$ (12.37 for women vs. 14.06 for men, $p<0.05$ ), and higher WBC, and triglyceride concentration. All the markers were inversely related to age (younger patients had a higher value). In addition, we found BMI inversely related to HDL concentration and expectedly patient on statin treatment had lower cholesterol concentration compared to those not on statin treatment. The inverse association between aspirin and cholesterol is due to the fact that in this clinic the statins proportion combined with aspirin.

\section{Association between blood biomarkers and chronic respiratory symptoms (CRS)}

The association between blood biomarkers and CRS is shown in Table 3 . We have observed that only a weak association between biomarkers of glycaemic measure (i.e. FPG and $2 \mathrm{hrs}$ PG) and dyspnea exist. For instance, $10 \mathrm{mg} / \mathrm{dl}$ increase in FPG was associated with a 7\% increase in the risk of dyspnea. There were no significant associations with other CRS component.

Association between blood biomarkers and lung function No significant relationship between blood biomarkers and measures of lung function were documented except

Table 2 Biomedical indicator of systemic inflammation, glycaemic control and fat profile of diabetic subjects

\begin{tabular}{|c|c|c|c|c|c|c|}
\hline & \multicolumn{2}{|c|}{ Women } & \multicolumn{2}{|l|}{ Men } & \multicolumn{2}{|c|}{ Total } \\
\hline & $\mathrm{N}$ & Mean (SD) & $\mathrm{N}$ & Mean (SD) & $\bar{N}$ & Mean (SD) \\
\hline $\mathrm{FPG}, \mathrm{mg} / \mathrm{dl}$ & 189 & $146.88(54.66)$ & 252 & $141.37(52.14)$ & 441 & $441 ; 143.73(53.25)$ \\
\hline $2_{\text {hrs }} P G, m g / d l$ & 189 & $215.85(68.34)$ & 254 & 218.61 (73.52) & 443 & $443 ; 217.43$ (71.29) \\
\hline Hemoglobin, $\mathrm{g} /\left.\mathrm{dl}\right|^{*}$ & 122 & $12.37(1.52)$ & 155 & $14.06(2.14)$ & 277 & $277 ; 13.32(2.07)$ \\
\hline $\mathrm{HbA} 1 \mathrm{c}, \%$ & 112 & $8.86(2.21)$ & 157 & $8.84(2.15)$ & 269 & $269 ; 8.85$ (2.17) \\
\hline Cholesterol & 122 & $157.30(41.92)$ & 149 & $151.16(40.54)$ & 271 & $271 ; 153.93(41.21)$ \\
\hline Triglyceride & 141 & $133.47(60.10)$ & 166 & 135.59 (92.28) & 307 & $307 ; 134.61$ (79.03) \\
\hline $\mathrm{HDL}^{*}$ & 121 & $41.30(8.51)$ & 154 & $36.47(8.57)$ & 275 & $275 ; 38.60(8.86)$ \\
\hline WBC $\times 10 \wedge^{9} /$ Liter* $^{*}$ & 93 & $8.82(2.55)$ & 120 & $7.74(1.72)$ & 213 & $213 ; 8.21(2.18)$ \\
\hline
\end{tabular}

The differences between groups were tested using t-test and Wilcox on Man-Whitney as appropriate FPG fasting plasma glucose, $2_{h r s} P G 2 \mathrm{~h}$ post meal plasma glucose, $H D L$ High-density lipoprotein *Indicate $p<0.05$ 
Table 3 Association of selected biomarkers of glycaemic control, fat profile, and systemic inflammation with chronic respiratory symptoms (CRS)

\begin{tabular}{lllll}
\hline & Cough & Dyspnea & Allergy sym. & Asthma/COPD \\
& $N=62(7.17 \%)$ & $N=197(22.77 \%)$ & $N=112(12.95)$ & $N=26(3.01 \%)$ \\
\hline FPG $^{a}$ & $1.01(1.00-1.02)$ & $\mathbf{1 . 0 1 ( 1 . 0 0 - 1 . 0 2 )}$ & $1.00(1.00-1.01)$ & $1.00(0.98-1.01)$ \\
${ }_{2 h}$ PPG $^{a}$ & $1.00(1.00-1.01)$ & $\mathbf{1 . 0 0 ( 1 . 0 0 - 1 . 0 1 )}$ & $1.00(0.99-1.00)$ & $1.00(0.99-1.01)$ \\
Hemoglobin $^{b}$ & $1.05(0.81-1.35)$ & $0.96(0.77-1.20)$ & $0.92(0.71-1.18)$ & $1.03(0.70-1.50)$ \\
HbA1c $^{a}$ & $1.15(0.94-1.41)$ & $1.02(0.87-1.19)$ & $0.99(0.81-1.19)$ & $0.91(0.69-1.20)$ \\
Cholesterol $^{c}$ & $1.00(0.99-1.01)$ & $0.99(0.98-1.00)$ & $1.00(0.99-1.02)$ & $1.01(0.99-1.02)$ \\
Triglyceride $^{a}$ & $1.70(0.76-3.83)$ & $1.19(0.65-2.17)$ & $0.51(0.25-1.17)$ & $1.34(0.47-3.84)$ \\
HDL $^{d}$ & $0.98(0.92-0.92)$ & $0.98(0.94-1.02)$ & $1.04(0.99-1.08)$ & $1.04(0.98-1.12)$ \\
WBC $^{a}$ & $3.09(0.51-18.92)$ & $1.37(0.37-5.12)$ & $0.35(0.06-1.96)$ & $1.37(0.12-16.10)$ \\
\hline
\end{tabular}

FPG Fasting plasma glucose, $2_{\text {hrs }} P P G 2$ hrs. Post meal plasma glucose

All variables are Odds Ratio $(95 \% \mathrm{Cl})$

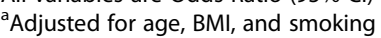

${ }^{\mathrm{b}}$ Adjusted for age, gender BMI, and smoking

'Adjusted for age, BMI, smoking, aspirin, and statin

${ }^{\mathrm{d}}$ Adjusted for age, gender, BMI, smoking, and aspirin

Bold "OR" are significant at $p<0.05$

between $\mathrm{HDL}$ and \%FVC (but not with $\mathrm{FEV}_{1}$, see Table 4$)$. In addition, one SD $(=8.86 \mathrm{mg} / \mathrm{dl})$ increase in HDL was associated with a $6.22 \%(0.18-12.27)$ increase in \%FVC.

We did not find any differences in this relationship with age (cut point 46 years), gender, and BMI (either cut point 23 and 25) groups (Fig. 1).

\section{Discussion}

We found that glycaemic measures (i.e. high fasting and post-meal plasma glucose) linked to risk of dyspnea. HDL concentration was directly associated with \%FVC. Unlike a study in Korea [26], we did not find significant age or gender differences in the association between HDL and \%FVC (Fig. 1). This association was also independent of overall or central obesity. Our result was robust to additional adjustment for exogenous confounding factors (such as temperature and cigarettes smoke) and consistent with a study from France [27] showing HDL as an

Table 4 Association between lung function (measured and \% predicted) and selected blood biomarkers

\begin{tabular}{|c|c|c|}
\hline & $\% \mathrm{FEV}_{1}$ & $\% \mathrm{FVC}$ \\
\hline $\mathrm{FPG}, n=329$ & $-0.01(-0.05-0.03)$ & $0.00(-0.04-0.03)$ \\
\hline $2_{\text {hrs }} P P G, n=334$ & $0.00(-0.20-0.03)$ & $0.01(-0.01-0.03)$ \\
\hline Hemoglobin, $n=202$ & $-0.55(-2.06-0.97)$ & $-0.06(-1.50-1.38)$ \\
\hline $\mathrm{HbA1c}, n=200$ & $-0.01(-1.09-1.06)$ & $-0.22(-1.26-0.82)$ \\
\hline Cholesterols, $n=197$ & $0.02(-0.04-0.08)$ & $0.04(-0.02-0.10)$ \\
\hline Triglyceride ${ }^{a}, n=234$ & $0.58(-4.51-3.35)$ & $-0.98(-4.72-2.77)$ \\
\hline $\mathrm{HDL}, n=202$ & $0.00(-0.28-0.28)$ & $0.27(0.08-0.53)$ \\
\hline WBC, $n=160$ & $-1.04(-11.59-9.50)$ & $1.60(-8.44-11.64)$ \\
\hline
\end{tabular}

All variables are Coefficient (95\% Confidence Interval)

${ }^{a}$ variables are natural logarithm

Bold "value" are significant at $p<0.05$ independent predictor of \%FVC. Also similar to a study from Italy [28], we demonstrate that HDL is associated with impaired lung function in a mainly restrictive pattern. Other studies have also shown an association with metabolic syndrome [16] and low HDL [27] and restrictive, but not an obstructive respiratory pattern.

Mechanisms underlying diabetes lung defect are not fully clear. Glycosylation of protein in a patient with poor metabolic control leads to the accumulation of collagen in lung connective tissue [5]. The lung collagen accumulation and increased stiffness of lung parenchyma and chest wall may cause the restrictive functional defect appearing in lung disease. Studies have suggested that impaired pulmonary function may be a potential risk factor for type 2 diabetes [29], where the underlying mechanisms closely linked to an excess of oxidative stress and chronic low-grade inflammation [30, 31]. Inflammatory markers such as C-reactive protein (CRP) have been associated with impaired pulmonary function among subjects with diabetes [32]. In contrast, HDL may have a positive effect through its role in immune regulation. HDL has been shown to bind to bacterial endotoxin as well as to relieve inflammation [33, 34], suggesting a potential role for $\mathrm{HDL}$ in preventing lung tissue damage. In the present study WBC, a marker of nonspecific systemic inflammation was not associated with HDL.

\section{Conclusion}

It is difficult to draw a clear conclusion about the cause-effect relationship or clinical impact based on this study alone. Further studies are required to clarify the causal relationship and to assess clinical outcomes including long-term changes in lung function. Specifically, 


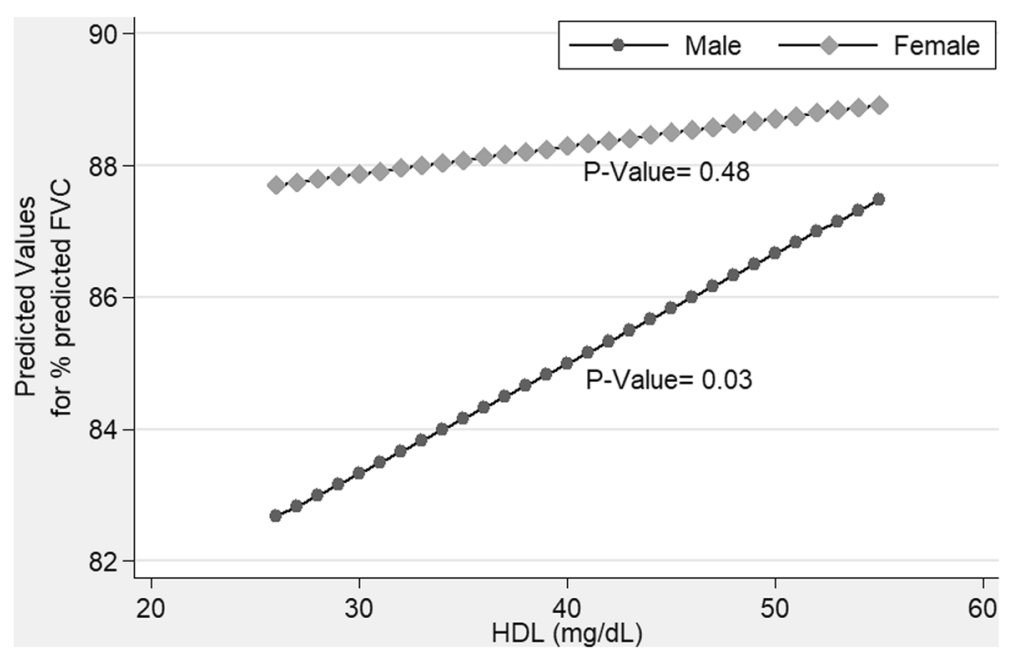

Fig. 1 Association between HDL and Forced Vital Capacity among men and women

the finding, if there is heterogeneity in the association between a biomarker of interest and lung function pattern across patients with Asthma and COPD, could be indicative and would provide us with a better understanding of the mechanism of diseases. Since the high rate of respiratory disease is under-diagnosed, identification of clinically meaningful elements for developing a screening program is critical.

\section{Abbreviations}

ARDS: Acute respiratory distress syndrome; CRF: Chest Research Foundation; CRP: C-reactive protein; CRS: Chronic respiratory symptoms; DM: Diabetes mellitus; ECSC: European Community for Steel and Coal; KEM: King Edward Memorial

\section{Acknowledgements}

Data obtained in this manuscript is partly from a Ph.D. thesis project entitled "A study to evaluate the plausible mechanism of air pollution effect on diabetes". We acknowledge the patients that participated in this study.

\section{Funding}

The study was supported by The Wellcome Trust, London, UK.

\section{Availability of data and materials}

The datasets generated during and/or analyzed during the current study are available from the corresponding author on reasonable request.

\section{Authors' contributions}

MAK, SS, and CSY researched, wrote, discussed and edited the manuscript. FR and BK contributed to the analysis plan and edited the manuscript. MAK is the guarantor of this work and, as such, had full access to all the data in the study and takes responsibility for the integrity of the data and the accuracy of the data analysis. All authors read and approved the final manuscript.

\section{Ethics approval and consent to participate}

The study approved by the Ethical Committee, King Edward Memorial Hospital Research center (ref no. KEMHRCNSP/Dir. Off/EC/145). Type 2 diabetic subjects attended diabetes care unit of King Edward Memorial (KEM) hospital and consented to participate in the study.

\section{Competing interests}

The authors declare that they have no competing interests. SS is member of the Editorial Board of Multidisciplinary Respiratory Medicine.

\section{Publisher's Note}

Springer Nature remains neutral with regard to jurisdictional claims in published maps and institutional affiliations.

\section{Author details}

'Social Determinants of Health Research Center, Ahvaz Jundishapur University of Medical Sciences, Ahvaz, Iran. ${ }^{2}$ Department of Public Health, Faculty of Health, Ahvaz Jundishapur University of Medical Sciences, Ahvaz, Iran. ${ }^{3}$ Chest Research Foundation (CRF), Pune, Maharashtra, India. ${ }^{4}$ King Edward Memorial Hospital Research Center, Pune, Maharashtra, India. ${ }^{5}$ Thalassemia and Hemoglobinopathy Research Centre, Health Research Institute, Ahvaz Jundishapur University of Medical Sciences, Ahvaz, Iran. ${ }^{6}$ Department of Statistics, Omidieh Branch, Islamic Azad University, Omidieh, Iran.

Received: 9 December 2018 Accepted: 24 April 2019

Published online: 01 July 2019

\section{References}

1. Hills AP, Arena R, Khunti K, Yajnik CS, Jayawardena R, Henry CJ, Street SJ, Soares MJ, Misra A. Epidemiology and determinants of type 2 diabetes in South Asia. Lancet Diabetes Endocrinol. 2018;6(12):966-78.

2. Hills AP, Misra A, Gill JMR, Byrne NM, Soares MJ, Ramachandran A Palaniappan L, Street SJ, Jayawardena R, Khunti K, et al. Public health and health systems: implications for the prevention and management of type 2 diabetes in South Asia. Lancet Diabetes Endocrinol. 2018;6(12):992-1002.

3. Aswathy S, Lohidas V, Paul N, Anish TS, Narayanan T, Oldenburg B. Prevalence and social determinants of type 2 diabetes in a coastal area of Kerala, India. J Endocrinol Diabetes. 2017;4(3). https://doi.org/10.15226/ 12374-16890/15224/15223/00181

4. Misra A, Sattar N, Tandon N, Shrivastava U, Vikram NK, Khunti K, Hills AP. Clinical management of type 2 diabetes in South Asia. Lancet Diabetes Endocrinol. 2018;6(12):979-91.

5. Pitocco D, Fuso L, Conte EG, Zaccardi F, Condoluci C, Scavone G, Incalzi RA, Ghirlanda G. The diabetic lung - a new target organ? Rev Diabet Stud. 2012; 9(1):23-35.

6. Gong MN, Thompson BT, Williams P, Pothier L, Boyce PD, Christiani DC. Clinical predictors of and mortality in acute respiratory distress syndrome: potential role of red cell transfusion. Crit Care Med. 2005; 33(6):1191-8.

7. Iscimen R, Cartin-Ceba R, Yilmaz M, Khan H, Hubmayr RD, Afessa B, et al. Risk factors for the development of acute lung injury in patients with septic shock: an observational cohort study. Crit Care Med. 2008:36(5):1518-22.

8. Moss M, Guidot DM, Steinberg KP, Duhon GF, Treece P, Wolken R, et al. Parsons PE. Diabetic patients have a decreased incidence of acute respiratory distress syndrome. Crit Care Med. 2000;28(7):2187-92. 
9. Yu S, Christiani DC, Thompson BT, Bajwa EK, Gong MN. Role of diabetes in the development of acute respiratory distress syndrome. Crit Care Med. 2013;41(12):2720-32.

10. Marquis K, Maltais F, Duguay V, Bezeau AM, LeBlanc $P$, Jobin J, et al. The metabolic syndrome in patients with chronic obstructive pulmonary disease. J Cardpulm Rehabil. 2005;25(4):226-32. discussion 233-224.

11. Watz H, Waschki B, Kirsten A, Muller KC, Kretschmar G, Meyer T, et al. The metabolic syndrome in patients with chronic bronchitis and COPD: frequency and associated consequences for systemic inflammation and physical inactivity. Chest. 2009;136(4):1039-46.

12. Mafort TT, Rufino R, Costa CH, Lopes AJ. Obesity: systemic and pulmonary complications, biochemical abnormalities, and impairment of lung function. Multidiscip Respir Med. 2016;11(1):28.

13. Rana JS, Mittleman MA, Sheikh J, Hu FB, Manson JE, Colditz GA, et al. Chronic obstructive pulmonary disease, asthma, and risk of type 2 diabetes in women. Diabetes Care. 2004;27(10):2478-84.

14. Lee CT, Mao IC, Lin CH, Lin SH, Hsieh MC. Chronic obstructive pulmonary disease: a risk factor for type 2 diabetes: a nationwide population-based study. Eur J Clin Investig. 2013;43(11):1113-9.

15. Ehrlich SF, Quesenberry CP Jr, Van Den Eeden SK, Shan J, Ferrara A. Patients diagnosed with diabetes are at increased risk for asthma, chronic obstructive pulmonary disease, pulmonary fibrosis, and pneumonia but not lung cancer. Diabetes Care. 2010;33(1):55-60.

16. Fimognari $F L$, Pasqualetti $P$, Moro L, Franco A, Piccirillo G, Pastorelli R, et al. The association between metabolic syndrome and restrictive ventilatory dysfunction in older persons. J Gerontol A Biol Sci Med Sci. 2007;62(7):7605.

17. Tiengo A, Fadini GP, Avogaro A. The metabolic syndrome, diabetes and lung dysfunction. Diabetes Metab. 2008;34(5):447-54.

18. van den Borst B, Gosker HR, Zeegers MP, Schols AM. Pulmonary function in diabetes: a metaanalysis. Chest. 2010;138(2):393-406.

19. Fumagalli $G$, Fabiani $F$, Forte $S$, Napolitano M, Marinelli $P$, Palange $P$, et al. INDACO project: a pilot study on incidence of comorbidities in COPD patients referred to pneumology units. Multidiscip Respir Med. 2013;8(1):28.

20. Zheng H, Wu J, Jin Z, Yan L-J. Potential biochemical mechanisms of lung injury in diabetes. Aging Dis. 2017;8(1):7-16.

21. Liang JQ, Ding CH, Ling YL, Xu HB, Lu P, Xian XH. The protective function of puerarin to the injury of the lung and its mechanisms during diabetes. Zhongguo Ying Yong Sheng li Xue Za Zhi. 2007;23(3):355-8.

22. Miller MR, Hankinson J, Brusasco V, Burgos F, Casaburi R, Coates A, et al. Standardisation of spirometry. Eur Respir J. 2005;26(2):319-38.

23. Khafaie MA, Yajnik CS, Salvi SS, Ojha A. A study to evaluate the plausible mechanism of air pollution effect on diabetes. (PhD), Savitribai Phule Pune University, Retrieved from http://hdl.handle.net/10603/195346.

24. Khafaie MA, Salvi SS, Yajnik CS, Ojha A, Khafaie B, Gore SD. Air pollution and respiratory health among diabetic and non-diabetic subjects in Pune, Indiaresults from the Wellcome Trust genetic study. Environ Sci Pollut Res Int. 2017;24(18):15538-46.

25. Quanjer PH, Tammeling GJ, Cotes JE, Pedersen OF, Peslin R, Yernault JC. Lung volumes and forced ventilatory flows. Report working party standardization of lung function tests, European Community for steel and coal. Official statement of the European Respiratory Society. Eur Respir J Suppl. 1993;16:5-40.

26. Choi JH, Park S, Shin YH, Kim MY, Lee YJ. Sex differences in the relationship between metabolic syndrome and pulmonary function: the 2007 Korean National Health and nutrition examination survey. Endocr J. 2011;58(6):459-65.

27. Leone N, Courbon D, Thomas F, Bean K, Jego B, Leynaert B, et al. Lung function impairment and metabolic syndrome: the critical role of abdominal obesity. Am J Respir Crit Care Med. 2009;179(6):509-16.

28. Rogliani P, Curradi G, Mura M, Lauro D, Federici M, Galli A, et al. Metabolic syndrome and risk of pulmonary involvement. Respir Med. 2010;104(1):47-51

29. Lazarus R, Sparrow D, Weiss ST. Baseline ventilatory function predicts the development of higher levels of fasting insulin and fasting insulin resistance index: the normative aging study. Eur Respir J. 1998;12(3):641-5.

30. Hotamisligil GS. Inflammation and metabolic disorders. Nature. 2006; 444(7121):860-7.

31. Nakanishi N, Yoshida H, Matsuo Y, Suzuki K, Tatara K. White blood-cell count and the risk of impaired fasting glucose or type $\|$ diabetes in middle-aged Japanese men. Diabetologia. 2002;45(1):42-8.
32. Mannino DM, Ford ES, Redd SC. Obstructive and restrictive lung disease and markers of inflammation: data from the third National Health and nutrition examination. Am J Med. 2003;114(9):758-62.

33. Gordon BR, Parker TS, Levine DM, Saal SD, Wang JC, Sloan BJ, et al. Low lipid concentrations in critical illness: implications for preventing and treating endotoxemia. Crit Care Med. 1996;24(4):584-9.

34. Navab M, Berliner JA, Watson AD, Hama SY, Territo MC, Lusis AJ, et al. The yin and Yang of oxidation in the development of the fatty streak. A review based on the 1994 George Lyman duff memorial lecture. Arterioscler Thromb Vasc Biol. 1996;16(7):831-42.

\section{Ready to submit your research? Choose BMC and benefit from:}

- fast, convenient online submission

- thorough peer review by experienced researchers in your field

- rapid publication on acceptance

- support for research data, including large and complex data types

- gold Open Access which fosters wider collaboration and increased citations

- maximum visibility for your research: over $100 \mathrm{M}$ website views per year

At BMC, research is always in progress.

Learn more biomedcentral.com/submissions 